Buana Sains Vol 20 No 1: 67 - 74, 2020

\title{
SINERGI PERANCANGAN ZONA KONSERVASI DAN REKREASI PADA KAWASAN MANGROVE PULAU GALANG
}

\author{
Yusuf Ariyanto \\ Arsitektur Interior, Fakultas Industri Kreatif, Universitas Ciputra Surabaya -Indonesia
}

\begin{abstract}
Galang Island region's potential development into a tourism area depends on the physical potential, diversity of flora and fauna and activities that support the economic sector for residents around Galang Island. There are two types of ecotourism development recommendations, one concerning conservation which aims to preserve ecosystems and the second is the use of natural beauty as tourism background and facilities that support the surrounding resident's economy. The problem is how the two tourism recommendations can work together and what kind of synergy the recommendations are like. Through identification stages of the flora and fauna types and analysis of the economic activities of residents around Galang Island, produce a mapping of the potential that can be developed into a tourism area. In the ideation stage, the potential analysis can be realized by functional zone, namely conservation zones, recreation zones and their relationship to regional boundaries and the synergy relationship formed through the circulation concept. By the zones and circulation concept, the visualization phase will be more detailed explaining by the atmosphere that was formed as a synergy form in the Galang Island region design
\end{abstract}

Keywords: : Design; potential; synergy; tourism; zone.

\section{Pendahuluan}

Proses pengembangan sektor pariwisata akan berhasil dengan optimal bila ditunjang oleh potensi daerah setempat baik berupa wisata alam maupun wisata buatan manusia. Selain itu dalam menjadikan obyek tujuan wisata, potensi pengembangan dapat berupa keindahan alam, tempat bersejarah, tata cara hidup bermasyarakat maupun upacara keagamaan. Sama halnya dengan kawasan konservasi pulau galang yang sampai sekarang cenderung tidak diperhatikan mengingat pulau ini menjadi area kontroversi antara Pemerintah Kota Surabaya dengan Pemerintah Kabupaten Gresik, sehingga penguasaan terhadap pulau ini masih diambil alih oleh Pemerintah Provinsi Jawa Timur (Musyaddad, 2015).

Sejauh ini potensi yang terdapat di Pulau Galang adalah ekosistem lingkungan mangrove baik dari jenis flora dan faunanya. Sejalan dengan kawasan konservasi dibeberapa daerah di Jawa Timur bahwa pulau inipun berpotensi untuk dijadikan kawasan ekowisata. Menurut Wahyono (2017), rekomendasi pengembangan pada obyek ekowisata mangrove adalah penyusun konsep berbasis ekowisata, pelatihan tentang mangrove, fasilitas dan pelayanan ekowisata, peningkatkan modal usaha, koordinasi antara Pemerintah dan pihak swasta dalam meningkatkan aksebilitas. Faktanya, 
Yusuf Arianto / Buana Sains Vol 20 No 1 : 67-74

terdapat 2 hal yang berbeda dari kelompok jenis rekomendasi diatas, satu mengenai bagaimana konservasi tersebut dapat menjaga kelestarian ekosistem yang ada dan yang kedua adalah eksploitasi terhadap keindahan alam tersebut dalam bentuk sarana dan fasilitas wisata untuk menunjang perekonomian warga sekitar.

Dari penjelasan diatas, memunculkan permasalahan bahwa apakah kedua kelompok jenis rekomendasi tersebut bertolak belakang atau saling berpengaruh, tentunya melalui studi dan analisa yang tepat kedua hal tersebut dapat saling bersinergi yang diwujudkan dalam bentuk perancangan zona kawasan. Adapun tujuan dari perancangan ini adalah mewujudkan kawasan mangrove di Pulau Galang ini menjadi kawasan yang ideal untuk mengkonservasi flora dan fauna endemik sekaligus menjadi tempat rekreasi bagi warga sekitar dengan nuansa alam mangrove. Dengan memahami hal tersebut maka diupayakan untuk perancangan ini agar tidak terlalu banyak membuat sarana (fasilitas) buatan yang dapat merusak ekosistem setempat, sehingga ruang lingkup perancangan ini hanyalah berupa usulan konsep zonasi beserta suasananya dengan penempatan beberapa fasilitas yang terbuat dari material ramah lingkungan.

\section{Metode Penelitian}

Dalam pembahasan mengenai sinergi desain sebagai bagian dari rekomendasi pengembangan potensi wisata di Pulau Galang ini memiliki proses pengerjaan yang akan mengacu pada metode umum sebuah tahap perancangan, khususnya desain berskala urban untuk mencapai optimalisasi dan validitas hasil penelitian dengan memperhatikan tahapan dibawah ini (Ariyanto, 2019).

1. Identifikasi

Tahapan pengumpulan data dan informasi sebagai data primer, mengklasifikasikan dan memetakan permasalahan serta menganalisisnya dengan sumber data sekunder.

2. Ideasi

Dalam analisa pada tahapan identifikasi akan menghasilkan sintesa yang sesuai dengan kondisi site eksisting, tahap ini yang dapat kita sebut dengan sinergi dari proses perancangan.

3. Visualisasi

Mewujudkan ide yang muncul dalam bentuk gambar (utama sebagai luaran penelitian tahap ini), atau bahkan skema rencana untuk mempermudah mengetahui hubungan sinerginya.

\section{Hasil dan Pembahasan}

Dalam penelitian ini proses pengerjaannya akan mengacu pada metode umum sebuah tahap perancangan, terkhusus perancangan berskala urban untuk mencapai optimalisasi dan validitas hasil penelitian dengan memperhatikan tahapan dibawah ini.

\section{Identifikasi}

Tahapan pengumpulan data dan informasi sebagai data primer, mengklasifikasikan dan memetakan permasalahan serta menganalisisnya dengan sumber-sumber data sekunder.

Identifikasi terhadap view dari sisi Kota Surabaya adalah Pulau Galang dikelilingi badan air dengan dominasi vegetasi bakau diseluruh pinggir pulau dan menjadi view yang menarik bagi warga yang tinggal diseberang Pulau Galang yaitu warga Rusun Romokalisari. 
Yusuf Arianto / Buana Sains Vol 20 No 1 : 67-74

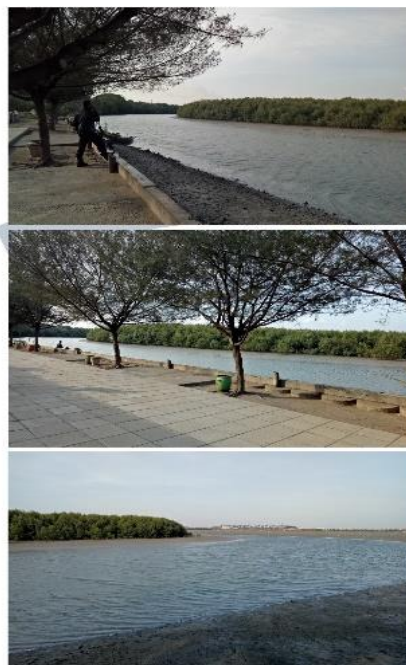

\section{VIEW EKSISTING}

Gambar 1. View dari batas sisi Kota Surabaya
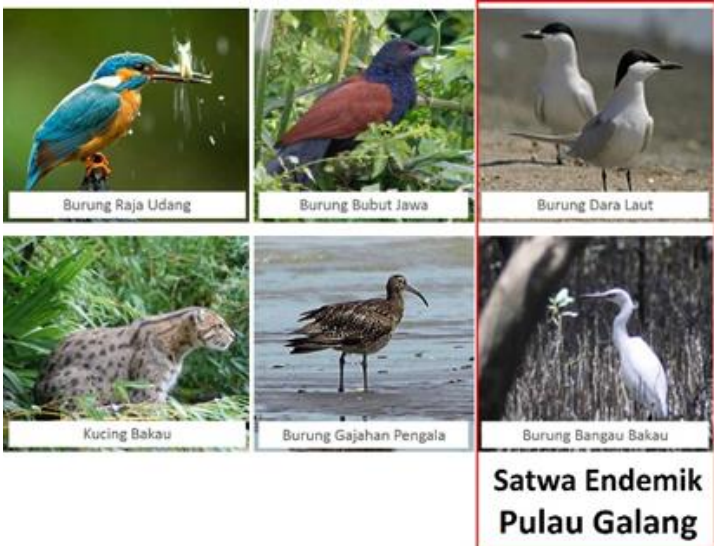

Gambar 2. Satwa Khas Mangrove Tanah Aluvial

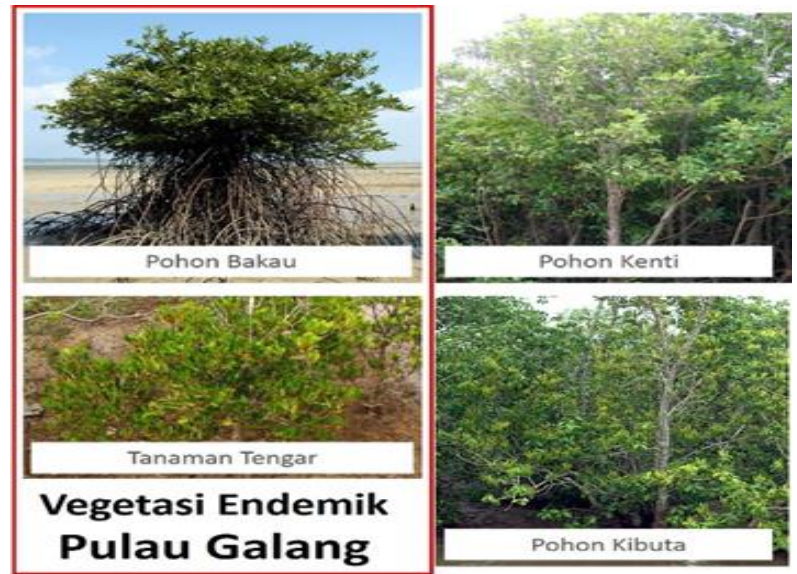

Gambar 3. Vegetasi Khas Mangrove Tanah Aluvial 
Yusuf Arianto / Buana Sains Vol 20 No 1 : 67-74

Sedangkan view dari sisi Kabupaten Gresik, lebih terlihat warga sudah melakukan sinergi dengan membangun anjungan papan kayu untuk menikmati alam Pulau Galang. namun nampak disisi ini vegetasi bakau tumbuh lebat Dari hasil survei dan pengamatan dilapangan didapatkan flora dan fauna endemik Pulau Galang yang mana masih umum terdapat di kawasan mangrove tanah aluvial. Untuk fauna terdapat burung dara laut dan burung bangau bakau serta flora terdiri dari pohon bakau dan tanaman tengar.

Oleh karena sifat yang khas sehingga konservasi terhadap flora dan fauna Pulau Galang perlu dilakukan untuk memastikan agar ekosistem tetap terjaga. Secara tidak langsung potensi diatas menjadi peluang yang baik untuk meningkatkan perekonomian warga sekitar. terlihat view dikedua sisi perbatasan wilayah daerah, meskipun belum terdapat pengaturan yang sah terhadap pengembangan Pulau Galang, warga sekitar sudah berinisiatif untuk membuat sarana-sarana wisata yang memiliki view dan terletak dipinggir Pulau Galang. Tidak jarang mereka juga mengunjungi Pulau Galang untuk mencari udang bakau yang terdapat dipesisir batas luar Pulau ini.

○ Ideasi

Dalam analisa pada tahapan identifikasi akan menghasilkan sintesa yang sesuai dengan kondisi site eksisting, tahap ini yang dapat kita sebut dengan sinergi dari proses perancangan. Dari kedua proses diatas menghasilkan parameter-parameter berkaitan dengan tata letak zona, macam fasilitas dan pemilihan material yang saling bersinergi.

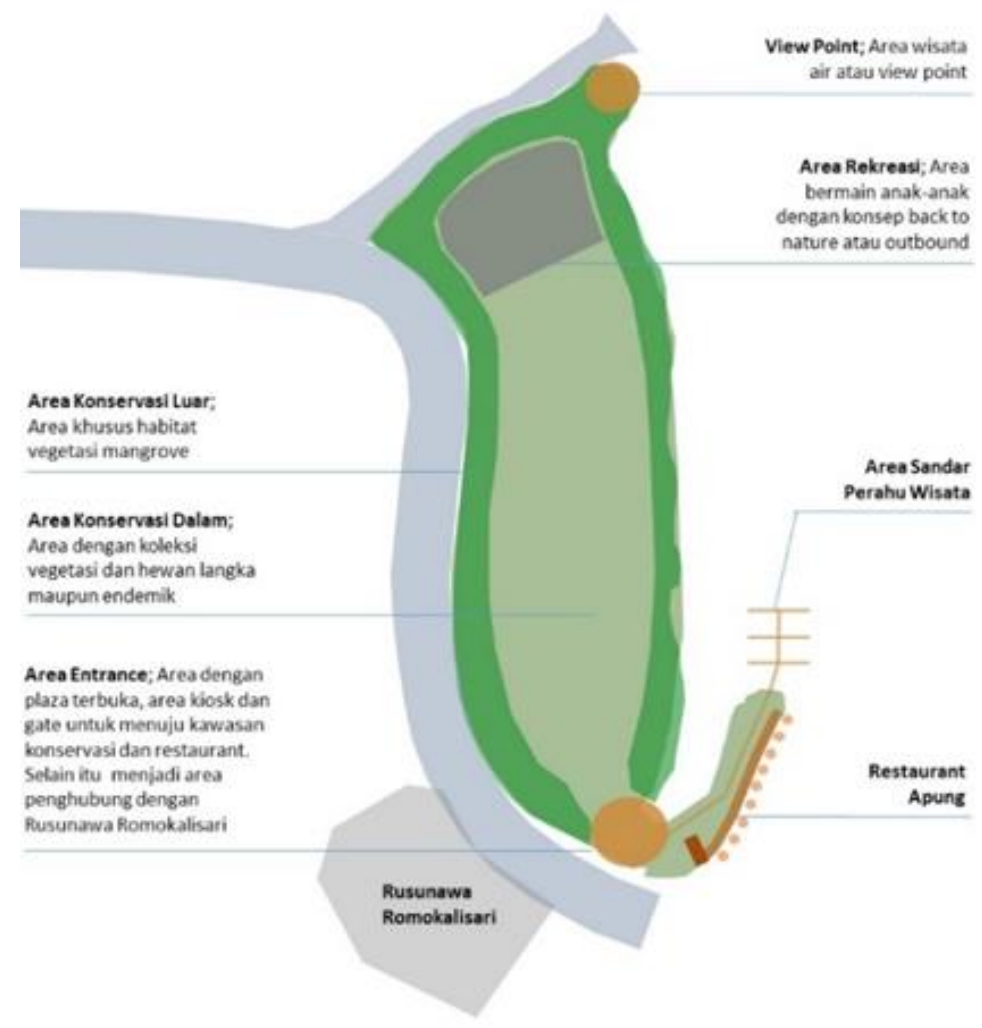

Gambar 4. Konsep zona pulau Galang 
Pada tahap ideasi zona ini terdapat pengelompokan area yang difungsikan untuk konservasi dan zona untuk kegiatan rekreasi. Zona konservasi terletak ditengah bagian pulau dengan pertimbangan, masih terjaganya ekosistem asli Pulau Galang yang ada ditengah pulau. untuk zona rekreasi terdapat di ujung Pulau, hal ini sebagai bentuk transisi dari masing-masing batas kota, sisi selatan memiliki ragam fungsi rekreasi kuliner guna menjembatani kebutuhan warga sekitar sisi Surabaya. sedangkan sisi utara lebih kepada area terbuka dengan beberapa hiburan menarik, sebab di batas sisi ini berbatasan langsung dengan pemukiman warga dan area industri yang cenderung tidak memiliki area RTH sebagai aktifitas berkumpul mereka. Sinergi antara kedua zona tercipta melalui sirkulasi yang saling terhubung, sehingga warga yang beraktifitas rekreasi di kedua ujung tetap dapat menikmati area konservasi sekaligus dapat menjadi sarana edukasi.

○ Visualisasi

Mewujudkan ide yang muncul dalam bentuk gambar (utama sebagai luaran penelitian tahap ini), atau bahkan skema rencana untuk mempermudah dalam mengetahui hubungan sinerginya.

Dalam tahap ini akan nampak seluruh Pulau Galang dengan pembagian zonanya yang terlihat dari perspektif mata burung (bird eye view). Terlihat pula detail-detail suasana yang ada di kedua zona dengan sarana atau fasilitas pendukungnya. Dari gambar suasana diketahui bahwa selain terdapat zona yang berbeda, adapula yang sebagian area yang bergabung.

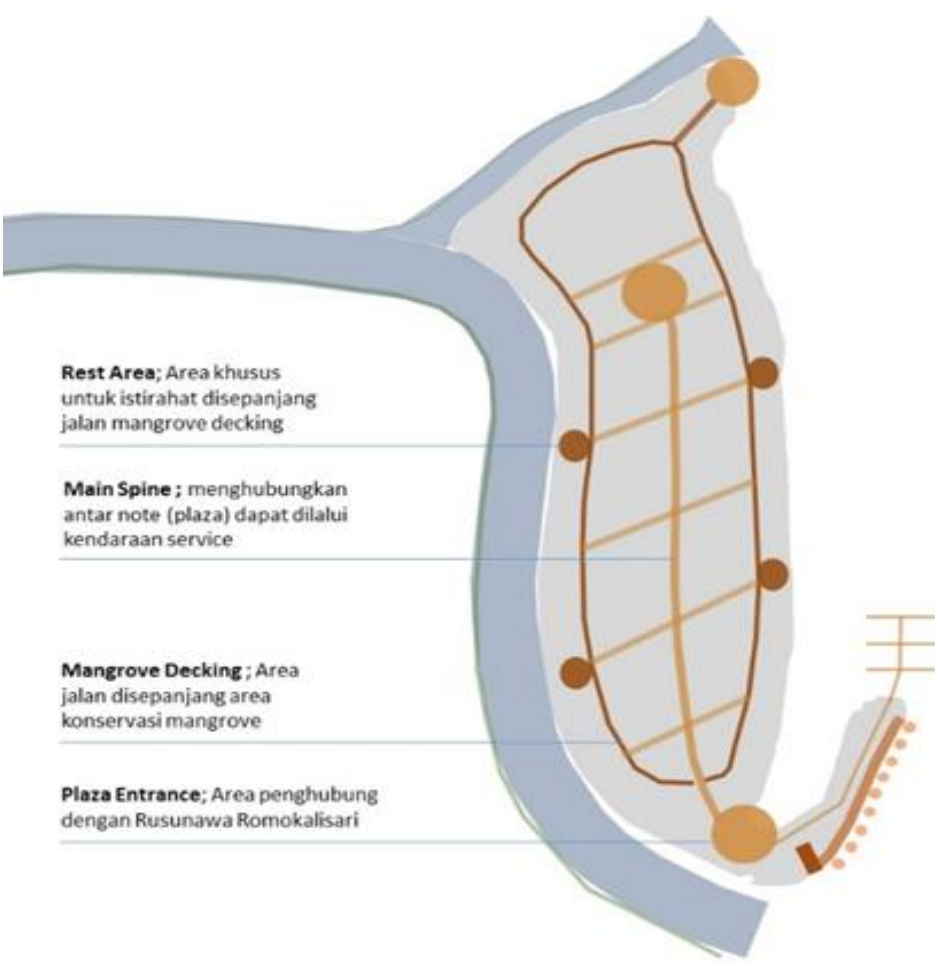

Gambar 5. Konsep sirkulasi Pulau Galang 


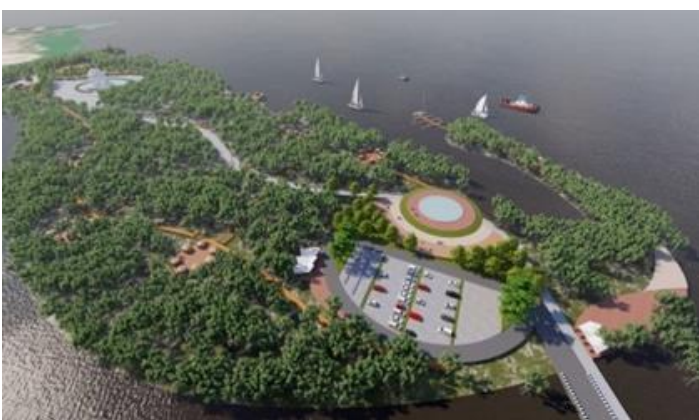

Gambar 6. Site Plan Pulau Galang (Bird Eye View)

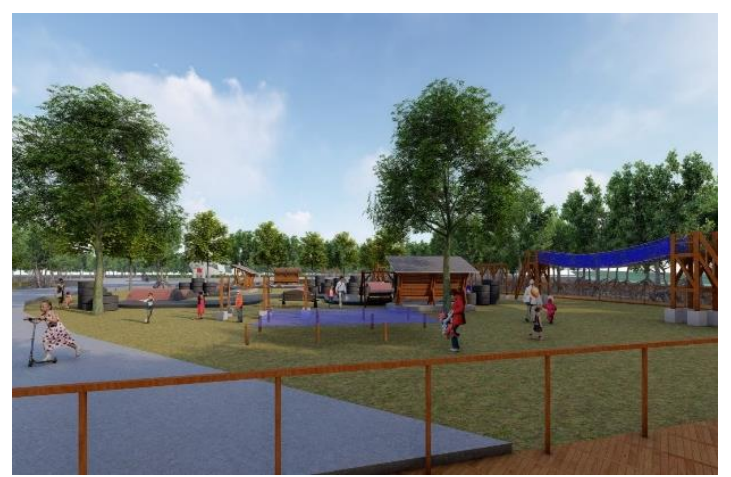

Gambar 7. Suasana Ruang Terbuka Zona Rekreasi

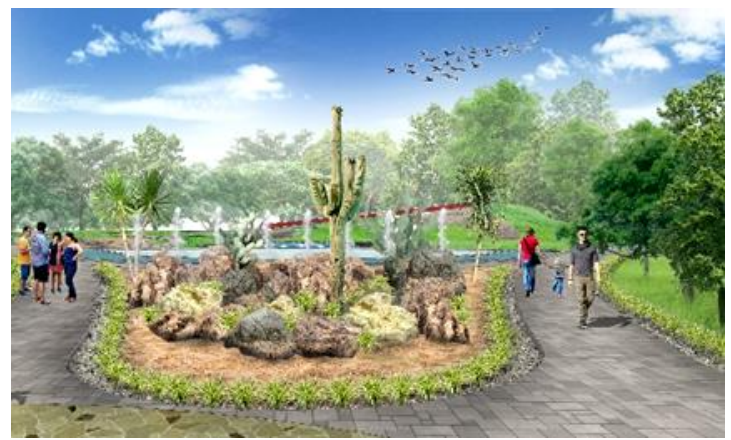

Gambar 8. Suasana Zona KonservasiPulau Galang

Beberapa jenis fasilitas seperti tempat parkir, plaza pertunjukkan, gazebo restaurant adalah sarana yang dihadirkan guna mendukung sektor ekonomi warga sekitar. namun terlihat sarana tersebut tidak membuat banyak eksploitasi terhadap zona konservasi, sebaliknya didalam zona rekreasi masih terdapat pula jenis-jenis flora yang dipertahankan.
Begitupula untuk material jalurjalur sirkulasi yang sama sekali tidak merusak eksistensi dari flora, terlihat seperti beberapa anjungan yang dibuat diatas area perairan. konsep jalur sirkulasi tersebut terinspirasi dari karakter fisik dari pohon mangrove yang mengikatkan akar atau pondasinya untuk mengurangi abrasi atau pengikisan tanah oleh air laut.

Salah satu area terbuka untuk aktifitas rekreasi bagi warga terletak 
diseberang sisi batas Kabupaten Gresik. dengan diperlengkapi sarana rekreasi menara pandang dan permainan flying fox untuk meningkatkan daya tarik pengunjung.

Selain itu, di zona konservasi terdapat jalur sirkulasi dengan material yang batu belah, selain alasan lowmaintenance juga mengekspresikan kekayaan alam sehingga nyaman untuk digunakan atau difungsikan. terdapat pula beberapa vegetasi asli dan pohon-pohon baru ditanam guna membuat suasana nyaman untuk difungsikan. dengan memperhatikan desain lansekap dan pemilihan vegetasi yang membuat semakin bervariasi dan membuat warga yang mengunjungi tempat ini mendapat pengalaman baru.

\section{Dampak Dan Manfaat Kegiatan}

Dalam proses perancangan sinergi zona kawasan mangrove pulau galang ini dapat menjadi tolak ukur proses perancangan dan studi preseden untuk obyek ekowisata yang serupa atau obyek wisata yang mempertentangkan mengenai kebutuhan ekonomi dengan pelestarian lingkungan.

Selain itu, tentunya hasil dari perancangan ini dapat dijadikan pedoman untuk mengembangkan kawasan konservasi dan wisata mangrove di pulau galang ini dengan melibatkan pihak Pemerintah Kota - Kabupaten, Provinsi bahkan kerjasama program CSR dengan pihak swasta.

\section{Kesimpulan}

Usulan sinergi desain zona konservasi dan zona rekreasi pada Pulau Galang diwujudkan dalam bentuk tata zona yang sesuai dengan posisi dan jenis ekosistem eksisting Pulau Galang serta zona rekreasi yang diidentifikasi sesuai dengan aktifitas dan kebutuhan warga sekitar Pulau Galang. Adapun bentuk sinergi yang dapat diusulkan adalah dengan menghubungkan zona konservasi dengan zona rekreasi, hal ini terwujud dalam tata zona dan konsep sirkulasi serta penempatan fasilitas yang sesuai fungsi zona tersebut. Konsep sinergi dalam usulan desain ini tentunya dapat menjadi jawaban mengenai konsep pengembangan ekowisata di kawasan mangrove ditempat lain.

\section{Ucapan Terimakasih}

Terima kasih kepada pihak-pihak yang membantu dalam terwujudnya penelitian ini, terkhusus kepada Universitas Ciputra Surabaya, PT. Tata Matra Indonesia (Biro Konsultan Arsitektur), Pemerintah Provinsi Jawa Timur, PT. Pelindo III serta warga sekitar kawasan konservasi mangrove Pulau Galang.

\section{Daftar Pustaka}

Musyaddad, Achmad Azmi. 2015. Perebutan Kepemilikan Pulau Galang Di Perbatasan Surabaya Gresik. Masters Thesis. Surabaya : Universitas Airlangga.

Wahyono, Windy Hera, dan Dian Rahmawati. 2017. Preferensi Stakeholder dalam Pengembangan Ekowisata Mangrove Gunung Anyar Surabaya. Jurnal Teknik ITS 6 (2) : A662 - A664.

Ariyanto, Yusuf. 2019. Identifikasi Potensi Jenis Komersial pada Lahan Aset Dinas Perhutani yang Berkontur. Jurnal Aksen 4 (1) : 5 - 17. Universitas Ciputra Surabaya.

Riverdale \& IDEO. (2011). Design Thinking for Educators : 4-8. 
Mukhlisi. 2017. Potensi Pengembangan Ekowisata Mangrove di Kampung Tanjung Batu, Kecamatan Derawan, Kabupaten Berau. Jurnal Manusia \& Lingkungan 24 (1) : 23-30. 